DOI: https://doi.org/10.24867/11FA03Nikolic

\title{
IDEJNO ARHITEKTONSKO REŠENJE OBJEKTA MEŠOVITE NAMENE PO PRINCIPIMA COWORKING-COLIVING TIPOLOGIJE
}

\section{CONCEPTUAL ARCHITECTURAL PROJECT OF A MIXED-USE BUILDING BASED ON COWORKING-COLIVING TYPOLOGY PRINCIPLES}

\author{
Dejana Nikolić, Fakultet tehničkih nauka, Novi Sad
}

\section{Oblast - ARHITEKTURA I URBANIZAM}

Kratak sadržaj - Ovaj rad bavi se fenomenom radnih prostora $i$ analizom coworking-coliving tipologije kao aktuelne teme savremene arhitekture.

Ključne reči: tipologija, coworking, coliving, radni prostor

Abstract - This paper is about workspaces phenomenon and the analysis of coworking-coliving typology as a popular topic in contemporary architecture.

Keywords: typology, coworking, coliving, workspace

\section{UVOD}

Rad predstavlja je projekat savremene kolektivne kuće za coworking i coliving, na trgu Slavija u Beogradu. Projekat je nastao tokom predmeta Savremene teorije i tehnologije primenjene na arhitekturu, urbanizam i dizajn. U okviru predmeta organizovana je studentska radionica koja je trajala 10 nedelja. Radionicu su organizovali i vodili profesori dr Jelena Atanacković Jeličić, dr Dejan Ecet i gostujući arhitekta iz Japana, profesor Šin Joko.

Teorijsko istraživanje o temi sprovedeno je tokom studentske razmene u Temišvaru, pod mentorstvom profesora Ane Marie Branee i Cristiana Blidaria. Rad bavi se fenomenom radnih prostora koji uključuju coworking i coliving. Kako rad više nije vezan za određenu lokaciju, postoji potreba za ažuriranjem i stvaranjem arhitektonskih prostora koji objedinjuju rad i stanovanje, kao i ostale svakodnevne životne aktivnosti.

Popularne tipologije coworkinga i colivinga predstavljaju opciju za privremeni rad i smeštaj za kreativne pojedince koji traže nezavisnost i nova životna iskustva, kako u lokalnim zajednicama tako i širom sveta.

Tokom trenutne situacije vezane za pandemiju virusa COVID19 i okolnosti koje izazivaju boravak u kućnoj izolaciji, kao i izbegavanje bilo kakvih kontakata i onemogućene mobilnosti, danas više nego ikad smo suočeni sa činjenicom da našim životnim prostorima treba veća fleksibilnost.

Svesni smo da rad od kuće ima svoje prednosti i mane, ali to nije održiv način rada zbog nedostatka atmosfere radnog prostora.

Takođe uviđamo da se određene promene u projektovanju radnih tipologija trebaju dogoditi, pre svega u projekto-

\section{NAPOMENA:}

Ovaj rad proistekao je iz master rada čiji mentor je bio dr Dejan Ecet, docent. vanju radnih prostora i takođe dodavanju prostora za rad u program projektovanja stambenih objekata.

Tipologija radnog prostora nije se bitno promenila od 1930.-ih godina kada su definisani određeni kriterijumi za projektovanje. Stanovanje i rad su ključne i osnovne potrebe svakog čoveka, glavne funkcije građene sredine i najzastupljenija arhitektonska tipologija. Kristijan Norberg Šulc objasnio je da sama reč stanovanje znači više od posedovanja krova nad glavom i određenog broja kvadratnih metara. Prema Šulcu, stanovanje značiodabrati specifičan prostor ličnog sveta koji čoveku omogućava da bude $i$ ispolji sve ono što ta osoba istinski jeste [1]. Danas stanovanje mora uključiti prostor za život i prostor za radi kao i njihovo neprestano preklapanje u međuprostorima.

\section{PROCES PROJEKTOVANJA I ISTRAŽIVANJA}

Zadatak studentske radionice bio je projektovati moderan objekat na trgu Slavija u Beogradu. Predviđeno je da objekat u osnovi prizemlja zauzima prostor od 500 kvadratnih metara, kako bi se omogućili svi potrebni sadržaji za nesmetano funkcionisanje i rad coworking centra, te dodatnih javnih i polu-javnih sadržaja. Ovakvu zgradu je bilo potrebno oblikovati, pozicionirati i integrisati u urbani i kulturni kontekst, poštujući duh mesta. Tipološka istraživanja o prostorima za rad i radne makete su glavni istraživački alati pri projektovanju. Ključno je naglasiti da se za proces projektovanja idejnog rešenja kao glavna metoda istraživanja koriste makete i tenkei figure. Koncept i pristup projekta temelje se na tradicionalnoj japanskoj arhitektonskoj praksi koristeći samo makete kao sredstvo istraživanja i prezentacije. Krajnja svrha ovog procesa jeste stvaranje zgrade koja sadrži kvalitetan prostor za život i rad na istoj lokaciji.

\subsection{Metodologija}

$\mathrm{U}$ istraživanju su korišćene sledeće metode: analiza, sinteza, komparativna i eksperimentalna metoda, kako bi se dobilo najrelevantnije kritičko mišljenje o ovoj temi.

Metodologija je predstavljena u vidu brainstorming istaživačke mape, na slici 1. Rezultat kritičkog razmišljanja nastao je prikupljanjem i obradom podataka, zatim preklapanjem tih informacija, što je dovelo do definicije tipologije radnog prostora i izrade idejnog projekta. Podaci su prikupljeni iz različitih izvora sa interneta, relevantnih knjiga, dokumentarnih filmova, ličnih istraživanja i ličnog iskustva. Cilj istraživanja jeste formulisati jedinstveni skup karakteristika koje radni prostor za coworking- 
coliving mora posedovati kako bi se osigurao kvalitetan i uravnotežen radni i životni prostor.

$\mathrm{Na}$ taj način postaje lakše stvoriti zgradu sa izbalansiranim radnim i životnim prostorom koji pružaju potreban mir, lično utočište i prostore pažljivo osmišljene za buduće privremene korisnike.

Definisana lista karakteristika biće zatim primenjena u predloženom projektu za coworking-coliving centar.

\subsection{Tipologija radnog prostora}

Tipologija radnog prostora i istorija radnog mesta su nedovoljno istražene teme. Poslovni prostori danas i dalje podsećaju na prostore fabričkih objekata. Nažalost, radni prostori u obliku tradicionalnih kancelarijskih prostora dugo se nisu razvijali. Nojfertove i druge poznate knjige o projektantskim smernicama daju nam malo informacija o antropološkim merama radnog prostora.

Standardi u arhitektonskom projektovanju radnih prostora su zastareli. Fokus im je na preporukama kako na primer treba predvideti skladišni prostor, prostor za kretanje unutar kancelarijskog prostora, postavljanje radnog materijala na pisaći sto, napraviti dodatni prostor za okretanje stolica, koristiti optimalne dimenzije pravougaonih i okruglih stolova, sa nekoliko primera o tome kako urediti aktivnu i pasivnu zonu. Ovi standardi razlikuju tri glavna tipa kancelarija zasnovana na hijerarhiji radnog položaja na: pojedinačnu kancelariju, zajedničku kancelariji i konferencijsku salu.

Kada razmišljamo o radnom prostoru različitih firmi koje poznajemo, na primer neke advokatske kompanije ili kreativne industrije, arhitektonske ili IT firme, dolazimo do zaključka da svi ti prostori izgledaju gotovo isto.

Uniformnost radnog prostora rasprostranjena je u svim oblastima. Digitalna tehnologija je radikalno promenila način na koji danas većina nas radi, ali fizički prostori u kojima provodimo većinu svog vremena nisu išli u korak s tom drastičnom transformacijom.

Kako bi imali jasniji uvid u situaciju na slici 2. dat je vremenski pregled razvoja radnog prostora.

\subsection{Coworking-coliving tipologija}

Priča o coworkingu započela je 2005. godine kada je softverski inženjer Bred Neuberg osnovao kolektivni prostor za rad u San Francisku. Njegova ideja bila je da objedini osećaj nezavisnosti i slobode rada sa osećajem zajednice i saradnje sa drugima. Paradoks je da frilenseri koji ne moraju da borave u kancelariji, koji su i postali frilenseri kako bi pobegli iz kancelarija i korporacija, sada svesno biraju i žele da borave i plaćaju kvalitetniji prostor za rad. Stvaranje prijatnog radnog okruženja za okupljanje kreativnih mislilaca postao je veliki i veoma unosan biznis. Od 2019. godine u svetu postoji desetak coworking kompanija i platformi za rad kao što su: WeWork, Impact Hub, Industrious, CocoHub, UpWork, Coworker, Remote itd. Njihove franšize rasprostranjene su širom sveta.

Tipologija radnog prostora današnjice i budućnosti treba da kombinuje posao, obrazovanje, slobodno vreme, stanovanje i blagostanje. Posao više nije lokacija. Možemo raditi sa bilo kog mesta dokle god je to održivo. Očigledno je da postoji hitna potreba za definisanjem i stvaranjem novih arhitektonskih tipologija koje imaju veze sa našom kulturom rada.

\subsection{Radni prostor za savremeni svet}

Arhitektura nije egzaktna nauka, arhitektonski prostor treba prvo doživeti da bi se shvatio. Svi smo definitivno iskustveno puno naučili iz ove situacije prinudnog rada od kuće koju je izazvala pandemija. Arhitekte će morati da odgovore na nove izazove u projektovanju radnih prostora, kako kolektivnih tako i kućnih radnih soba. Ovaj prisilni globalni eksperiment rada od kuće preispitaće naš dalji odnos prema radu i radnom prostoru. Moramo da prihvatimo tu neminovnu činjenicu o konstantnom individualnom razvoju i prilagođavanju u svim profesijama i svim uslovima života i rada.

Odstupanje od tradicionalne tipologije kancelarije u suštini jeste koncept coworkinga. Coworking je kompromis između tradicionalnog kancelarijskog rada $\mathrm{i}$ rada na daljinu. Reč coworking u sebi nosi značenje saradnje, komunikacije i zajedništva. Glavne vrednosti coworkinga su upravo saradnja, otvorenost, komunikacija i održivost. Coworking je zajednica istomišljenika. Coworking je za sve ljude, kreativce, frilensere, preduzetnike, digitalne nomade, umetnike, itd. Takvo šarenoliko okruženje treba da nadahne rad, pomogne da se povezuju sa drugima, stvara nove prilike za rad, podstiče na formiranje start-up i osnažuje na napredno razmišljanje i rad tačno tamo gde smo lično najproduktivniji.

Prostor koji nam je neophodan treba da poveže digitalno i fizičko, lokalno i globalno, rad i život, javni i privatni aspekt. Radni prostor danas je i vaš radni sto kod kuće, kancelarija u firmi, mesto u coworking prostoru, kafić $\mathrm{u}$ blizini, restoran, knjižara, takoreći bilo koje mesto gde možete smestiti osobu sa računarom.

Rešenje za novi arhitektonski program radnog prostora može biti u kombinovanju već poznatih prostornih planova poput pejzažnog plana, otvorenog plana $i$ zatvorenih planova, zatim sa mešanjem i preklapanjem privatnih kancelarija, zatvorenih kabina, uz formiranje prijatnih zona $\mathrm{u}$ međuprostoru. Coworking je trenutno najbliži težnjama koje imamo jer nam daje i strukturu i slobodu, priliku za lako umrežavanje, obogaćivanje društvenih i poslovnih krugova, stimuliše nam kreativnost i omogućava slučajne spontane susrete.

\subsection{Proces projektovanja coworking-coliving objekta}

Glavno sredstvo istraživanja pri projektovanju nastalog arhitektonskog dela je metoda istraživanja koja koristi radne konceptualne makete koje nastaju kao odgovor na dodeljene zadatke tokom studentske radionice sa profesorom iz Japana.

Makete ovde nemaju reprezentativnu ulogu konačnog projekta, što je uobičajen način kod arhitekata, njihova uloga je samo eksperimentalnog tipa kako bi se bolje shvatile mogućnosti za enterijer, strukturu i oblikovanje.

Na ovaj način bolje se razume prostor i brže donose odluke o nameni, funkcionalnosti, estetici i konstrukciji objekta. Maketa kao sredstvo za rad daje nam konkretne odgovore, jer i nepisano pravilo kaže da sve ono što se može napraviti od kartona može biti izrađeno i od betona. Kad je model dobro izveden, rešenje je jasno vidljivo pomoću nekoliko jednostavnih fotografija koje su najbolja vizuelna prezentacija. 
Maketa ovde služi za razumevanje mogućnosti unutrašnjeg prostora, uređenje funkcionalnih zona i kretanje kroz prostor. Iz tog razloga raspored tipskog stana nekonvencionalno započinje sa radnom zonom, a zatim nastavlja sa zonom dnevnog boravka i spavanja.

U Japanu se maketama dodaju pomoćne papirnate figure ljudi, prevozna sredstva, nameštaj, životinje i drugi dekor prilagođeni veličini modela. Takve papirne figure nazivaju se tenkei. Koriste se za oživljavanje imaginarnog prostora i tumačenje realne upotrebe prostora u budućnosti. Tenkei mi je pomogao da postavkom u maketi simuliram realnu situaciju pri korišćenju i tako logičnije rešim pozicioniranje funkcija u prostoru.

Studija volumena takođe je odrađena pomoću radnih maketa od stiropora. Sama lokacija donekle sugeriše oblik, tako da je oformljen objekat zasečen na uglu što jasno deli masu objekta po funkciji na javni i privatni deo, naglašavajući prizemlje i ulaz u objekat.

Uloga modela u procesu istraživanja verovatno pokazuje najviše značaja kada je u pitanju rešavanje konstrukcije objekta. Drveni štapići na radnim maketama predstavljaju linearne noseće elemente stubova i greda. Na primeru koji sam razvila preklapaju se dva poznata modela, armiranobetonski elementi i model Le Korbizjeove kuće Dom-ino.

Objekat je podeljen na javne i polu-javne prostore $u$ prizemlju i na krovu, i na 3 etaže za stanare-umetnike koji tu borave. Stanovi su organizovani u 3 visinska nivoa kako bi se jasnije razdvojile funkcije i omogućila potrebna privatnost. Oko glavne noseće konstrukcije od betona i stakla dodat je perforirani armirano betonski omotač dinamičnog rasporeda.

\subsection{Parametri projektovanja}

$\mathrm{Na}$ osnovu svega prethodno navedenog u dosadašnjem tekstu prikupljenom $\mathrm{u}$ fazi istraživanja sastavljen je popis potrebnih kriterijuma, karakteristika i prostora za tipologiju coworking zgrade, od kojih će se određeni deo implementirati u predloženom projektu.

Spisak potreba za coworking predviđa: mogućnost jednostavnog prilagođavanja prostora, zonu za privatni razgovor, zonu za individualni rad, puno dnevne svetlosti, zvučna izolacija, raznolikost izbora, odvojenu soba za sastanke, huddle room, toalete, zonu odmora, atelje, kreativnu laboratoriju sa 3d štampačima, galeriju, radionicu, konferencijsko-izložbenu salu, kafić, malu kuhinju, skype zonu, biblioteku, predvorje, recepciju, službenika za ugostiteljstvo, domaćina zajednice, fleksibilan prostor za zajedničke događaje, itd.

\subsection{Funkcionalna organizacija}

Koncept colivinga i coworkinga namenjen je pre svega mladim profesionalcima u dobi između 21 i 35 godina, jer će oni verovatno radije odabrati ovakav vid privremenog stanovanja sa dodatnim servisnim uslugama. Ovo bi uskoro moglo postati standardan način života i za druge starosne grupe gde bi boravili, živeli, radili i družili se. Trenutno se ova tipologija nalazi na svojevrsnom raskršću između tipologije studentskog smeštaja u univerzitetskom domu i tipologije hotela.

Prizemlje je otvoreno za javnost, uz ulaznu zonu nalazi se recepcija-kafić, coworking zona sa različitim opcijama za rad, vertikalnom komunikacijskom zonom, toaletom i mini kuhinjom. Predviđeno je da se radna zona može svakodnevno lako transformisati, pomoću kliznih zidnih elemenata, promenom rasporeda nameštaja, otvaranjem ili zatvaranjem prostornih segmenata zidnim panelima. Prizemlje je zamišljeno kao prostor za događaje coworking zajednice, slobodne aktivnosti poput prostora za časove kuvanja, časove plesa, umetničke i zanatske radionice, za kvalitetniji društveniji način života. Fokus je na zajednici, udobnosti i funkcionalnosti čime se podstiče efikasnost $\mathrm{i}$ produktivnost rada i kvalitet života.

Osnova sprata je tipska i ponavlja se na tri gornja nivoa. Osnova tipskog sprata organizovana je sa dva velika prostrana stana za umetnike ili digitalne nomade. Stanovi su prostrane jedinice sa kuhinjom, kupatilom, dnevnim boravkom, spavaćim prostorom i privatnim radnim prostorom-ateljeom. Prostor je prvenstveno namenjen umetnicima, ima veliku spratnu visinu i dobro je osvetljen uz pomoć velikih otvora. Zbog nedostatka pregrada $\mathrm{u}$ prostoru, može se koristiti i lako prilagođavati drugim svrhama. Ukoliko je potrebno, dodavanjem više nameštaja apartman postaje poput hostel sobe sa 3 ili 4 ležaja. Pre ulaza u oba stana u okviru proširenog hodnika dodate su zone za zajedničko druženje, sastanke i brainstorming soba sa malim zajedničkim toaletom i kuhinjom.

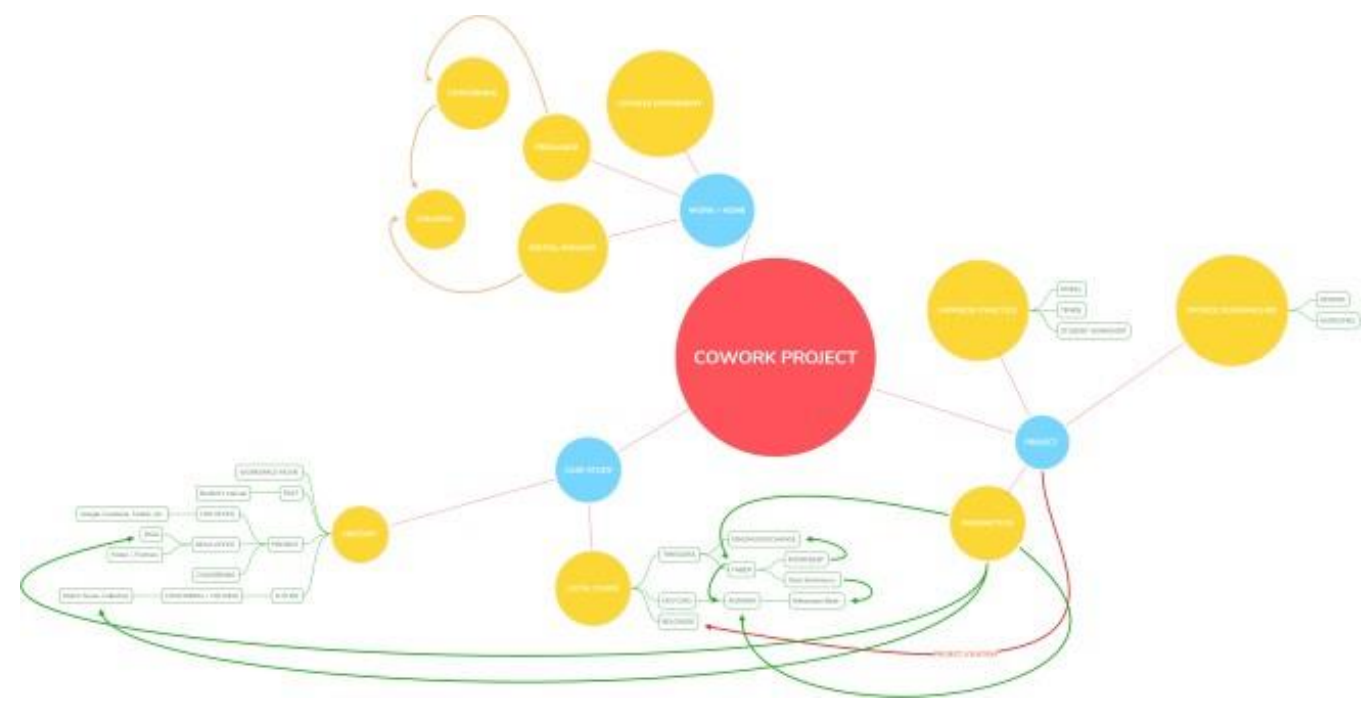

Slika 1. Istraživačka brainstorming mapa 


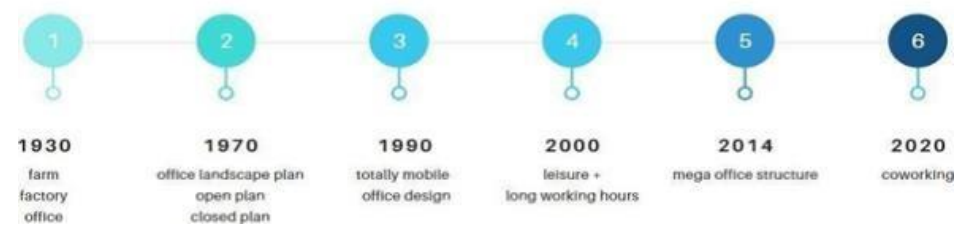

Slika 2. Vremenski pregled evolucije tipologije radnog prostora

Poslednji sprat je krovna terasa sa liftovskim pristupom, ima višestruku namenu kao: mesto za ručak, radno mesto, izložbeni prostor na otvorenom, prostor za zabavu, bioskop na otvorenom, i brojne druge mogućnosti za rad i uživanje. Na slici 3. prikazani su dijagrami objekta i predlog kako koristiti prostor ispred objekta i krovnu terasu.
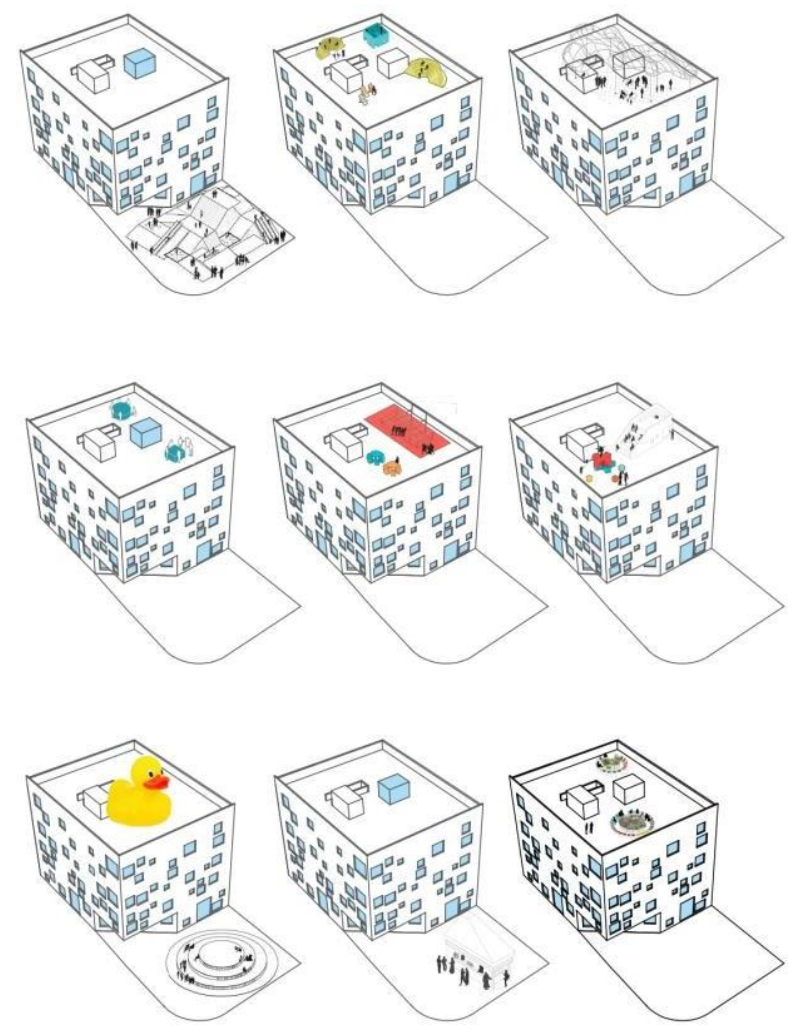

Slika 3. Dijagramski prikaz projektovanog objekta

\section{ZAKLJUČAK}

Coworking i coliving pokret su revolucija u svetu servisnih usluga i nekretnina. To je jednostavna, ali i složena tipologija sa dve ili više funkcija, koja ima ogroman rastući trend jer se tržište stambenog prostora udaljava od ustaljenog modela vlasništva i okreće ka uslužnom modelu baziranom na rentiranju po potrebi.
Jasno nam je da rad više nije povezan sa lokacijom i da postoji potreba za prilagođavanjem naših savremenih navika u projektovanju tipologije rada $\mathrm{i}$ stanovanja. Stanovanje bi trebalo da u budućnosti omogući laku transformaciju pojedinih delova u radni prostor po potrebi, a da pritom ne ugrozi njegovu tradicionalnu funkciju i ravnotežu između života i rada.

Postoji velika potreba za ažuriranjem i stvaranjem novih arhitektonskih prostora koji objedinjuju rad i stanovanje, kao i ostale svakodnevne životne aktivnosti. Coworking i coliving su trenutno najbolja opcija za savremeni rad i stanovanje za kreativne pojedince koji traže nezavisnost i nova životna iskustva, kako u lokalnim zajednicama tako i širom sveta.

"Dizajnirati je uvek i redizajnirati. Uvek postoji nešto što prvo postoji kao dato, kao prepreka, kao problem. Dizajnirati nešto je zadatak da napravite nešto živahnije, komercijalnije, korisnije, bolje za korisnika, više prihvatljivo, održivije i tako dalje, zavisno od raznih ograničenja na koja projekat mora da odgovori. Drugim rečima, uvek postoji nešto lekovito u dizajnu [2]."

\section{LITERATURA}

[1] Kristijan Norberg Šulc, Stanovanje: stanište, urbani prostor, kuća, Građevinska knjiga, Beograd, 1990.

[2] Latour Bruno. Lecture for the "Networks of Design" meeting of the Design History Society Falmouth, Cornwall, United Kingdom, 2008.

\section{Kratka biografija:}

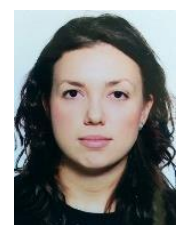

Dejana Nikolić rođena je u Novom Sadu 1993. god. Master rad na Fakultetu tehničkih nauka iz oblasti Arhitekture i urbanizma odbranila je 2020.god.

kontakt: dejana_nikolic@yahoo.com 